\title{
Positive outcomes of participatory ergonomics in terms of higher comfort and productivity
}

\author{
Peter Vink $^{\mathrm{a}, \mathrm{b}}$, Ernst A.P. Koningsveld ${ }^{\mathrm{b}}$, Johan F. Molenbroek ${ }^{\mathrm{a}}$ \\ a Delft University of Technology, Industrial Design Engineering, Landbergstraat 15, \\ 2628 CE Delft, The Netherlands \\ tel +31235549590 \\ fax +31235549305 \\ e-mail:P.Vink@arbeid.tno.nl \\ ${ }^{\mathrm{b}}$ TNO Quality of Life \\ P.O.box 718 \\ 2130 AS Hoofddorp
}

The Netherlands

Corresponding author: P.Vink, tel +31 23 5549590, e-mail: P.Vink@arbeid.tno.nl

\begin{abstract}
Ergonomics sometimes has a negative connotation as it is seen to be connected to illness or guidelines that limit innovations. This paper is focused on the positive aspects of ergonomics in improvement of the working environment. It consists of a part that studies the literature on success factors in the process towards higher productivity and greater comfort, the formulation of a model and a hypothesis, which is illustrated by four cases.

The model distinguishes the success factors in 'goal', 'involvement' and 'process'. Goals: evidence is found in the literature that a positive approach has benefits in terms of shareholder value and productivity, and for comfort. Involvement: the literature shows that participation of end-users and management contributes to success. Process: in the process it is essential to have a good inventory of the problems, a structured approach, a steering group responsible for the guidance, and end-users involvement in testing of ideas and prototypes.

It is hypothesized that the chance of success increases by empowerment (making the end-user responsible for deciding on the next step in the process) and positive experiences of end-users with the potential improvement (end-users feel or see the benefits). The four cases illustrate that the hypothesis can be used in evaluating cases.
\end{abstract}

Keywords: Comfort; Productivity; Participatory ergonomics; Experiencing alternatives

Paper published in Applied Ergonomics 37 (2006) 537-546 


\section{Good ergonomics is good economics}

In the view of a part of the public, ergonomics is coupled to illness, complaints or guidelines, which could have a negative connotation. One example is the introduction of a guideline for office chairs in the Netherlands. This guideline (NPR1813) prescribes exactly the adjustability ranges of the different parts of a chair based on the variation in anthropometrics in the Netherlands. Several designers, manufacturers and dealers complain that innovation is now restricted, because there is so much prescribed in detail (Office Forum, 2005). Another example is the discussion among 20 experts on future themes in manufacturing ergonomics (Vink and Stahre, 2005). One of the conclusions of this forum was that it is better to focus on health than on illness. Of course sometimes studies on risks can be helpful as well as ergonomic guidelines (e.g. ISO 9241-5:1998). However, stressing what is not allowed or prescribing certain formats is not motivating and limits innovativeness.

Another approach is to stress that system performance and health could be improved by applying ergonomics. This focus on health and overall system performance can also be found in the definition of the International Ergonomics Association (see http://www.iea.cc/ergonomics): Ergonomics (or human factors) is the scientific discipline concerned with the understanding of interactions among humans and other elements of a system, and the profession that applies theory, principles, data and methods to design in order to optimize human well-being and overall system performance.

The goal of this paper is to support ergonomists in applying the more positive approach to improve overall system performance. Hendrick (2001) also described several examples of positive effects of ergonomics and states 'good ergonomics is good economics'. Among a large diversity of positive effects of applying ergonomics, productivity and comfort are described in the literature. Positive effects of ergonomics are described in terms of higher productivity in manufacturing (e.g. Rosecrance, 2005; Looze et al., 2005) or in office work (Hedge and Sakr, 2005; Bauer et al., 2003). Productivity is in this case defined as described in the Cambridge Advanced Learner's Dictionary 2005: It is the rate at which a company or country makes goods, judged in connection with the number of people and the amount of materials necessary to produce the goods. Other positive effects like increasing comfort and thereby well-being for the end-users and sales for the manufacturer are also described (Eikhout et al., 2005; Vink, 2005). Comfort is defined as the convenience experienced by the end user during or just after working with the product (Vink, 2005). In all of the six studies mentioned (Rosecrance, 2005; Looze et al., 2005; Hedge and Sakr, 2005; Bauer et al., 2003; Eikhout et al., 2005; Vink, 2005), it was possible to increase sales or productivity in combination with better well-being or comfort. This should be interesting to more ergonomists and the society. However, it is not easy to achieve these goals and for gaining these successes more often, it is important to define the factors of importance to achieve this success. A universally agreed list of success factors is still missing. 


\section{Aim of this paper}

The aim of this paper is to find change process' factors that are important to achieve better comfort and higher productivity. Various studies have already been published on success factors, but there is no universally agreed list of factors. In this paper the available knowledge in the literature is discussed. Then four case studies are used as an illustration, and studied in depth to find potential explanations and additional success factors. The paper stresses the importance to pay attention to the positive aspects of ergonomics during a process of design, with a focus on the end-result of a design process. It is recommended to study this hypothesis further perhaps in a case control study.

\section{Available knowledge in literature}

A large number of studies are focused on productivity and comfort (Vink, 2005). Mostly, productivity and comfort are end results of a process in which end-users, experts (e.g. ergonomists), management and other staff play a role. Regarding this role of participants, some interesting visions from the literature regarding participation are described first. Secondly, the factors regarding an ideal approach (what are success factors) are described, as this is the aim of this paper. Finally, a hypothesis is made based on the findings in the literature regarding the positive approach (focused on productivity and comfort) and one or more of the success factors.

\subsection{Participation in the process towards better comfort and productivity}

The positive effects of participation have been demonstrated before and are also a reason to pay attention to this topic. The European Foundation for the Improvement of Living and Working Conditions (1999) reports that direct participation in production organizations most often leads to quality improvements (90\% of the cases), to reduction of throughput times ( $60 \%$ of the cases), and to reduction of costs ( $60 \%$ of the cases). Also comfort effects are described (Vink, 2005). However, these facts are merely estimations from experts. Apart from these estimations also more quantitative effects are found (Beevis and Slade, 2003; Koningsveld et al., 2005). Also, relationships between participation on the one hand and productivity or comfort on the other hand are described.

-Participation and productivity

The term 'productivity' entails many aspects. Recently Rhijn et al. (2005) described for instance four effects of a participatory approach related to productivity. The number of products per person per day was increased by $44 \%$, the order lead time was reduced $46 \%$, the direct time (time of added-value activities) was increased by $18 \%$ and the required workspace was reduced by $44 \%$. These specific effects are not new, but the general philosophy has proven its effect already in a study of 1999. In this study higher returns on investments are produced by companies that place workers at the core of their strategies than their industry peers. A study among 702 firms showed that better human resource 
attention is associated with an increase in shareholder wealth of 40,000 Euro per employee (Pfeffer and Veiga, 1999). The involvement of employees in a participatory process is thus also essential from a business perspective.

-participation and comfort

There is debate in the literature about the concept of comfort (Vink, 2005). However, the majority of the authors agree that comfort is of a subjective nature (Looze et al., 2003). The comfort or discomfort in a working environment can therefore only be evaluated by the user. An artifact in itself can never be comfortable. That is why much attention should be paid to how a user should be involved in the design process. The end-user should be involved, because he has unique insight into his task, work or activity. This involvement of stakeholders like the end-users is addressed in 'participatory ergonomics' (Wilson and Haines, 1997).

Participatory ergonomics is the discipline that studies how different parties should be involved in a design process. Participatory ergonomics is the adaptation of the environment to the human (that is ergonomics) together with the proper persons in question (participants) (Vink, 2005). Defined in this way participatory ergonomics is more an umbrella term under which different approaches are found. Kuorinka (1997) describes 'participatory ergonomics' as 'practical ergonomics with necessary actors in problem solving', which is close the previous definition. Wilson (1995) puts it into another perspective: 'It is the involvement of people in planning and controlling a significant amount of their own work activities, with sufficient knowledge and power to influence both processes and outcomes in order to achieve desirable goals'. Thus, Wilson stresses the fact that the employee should have control over his task, emphasizing also that participatory ergonomics is an umbrella concept. The common characteristic is that during the design process attention is paid explicitly to the role of employees, management, ergonomists and others involved. The difference in view is whether employees should be empowered or consulted in a participatory process. Some authors see the ideal participatory ergonomics approach as an approach where the employees are empowered to design and change their work station (e.g. Eklöf et al., 2004; Wilson et al., 1995). Others stress the consultation of end-users in a design process (e.g. Bronkhorst et al., 2005; Kuorinka, 1997). Simplified, we could state that one process is guided by the employees (they decide what will change) and the alternative approach is that the ergonomists or management leads the project and decides on the changes to be implemented. For both participatory ergonomics approaches well documented successes and failures can be found in the literature.

\subsection{Success factors in the process towards better comfort and productivity}

'Participatory ergonomics' includes a large variety of approaches and an interesting framework to classify the approaches has been developed by Haines et al. (2002). Apart from the classification it is also interesting to know what factors influence the chance of being successful. In various studies success factors were described (e.g. Looze et al. 2001; Koningsveld et al., 2005; Vink et al., 2005). These are: -arrange direct workers' participation, -arrange strong management support, 
-carry out a good inventory,

-use a step-by-step approach,

-arrange that a steering group is established with responsibilities,

-check the effects, including side effects in an early stage,

-do not focus only on health issues, and

-describe the cost: benefit ratio, not only in money but also with non-quantitative measures.

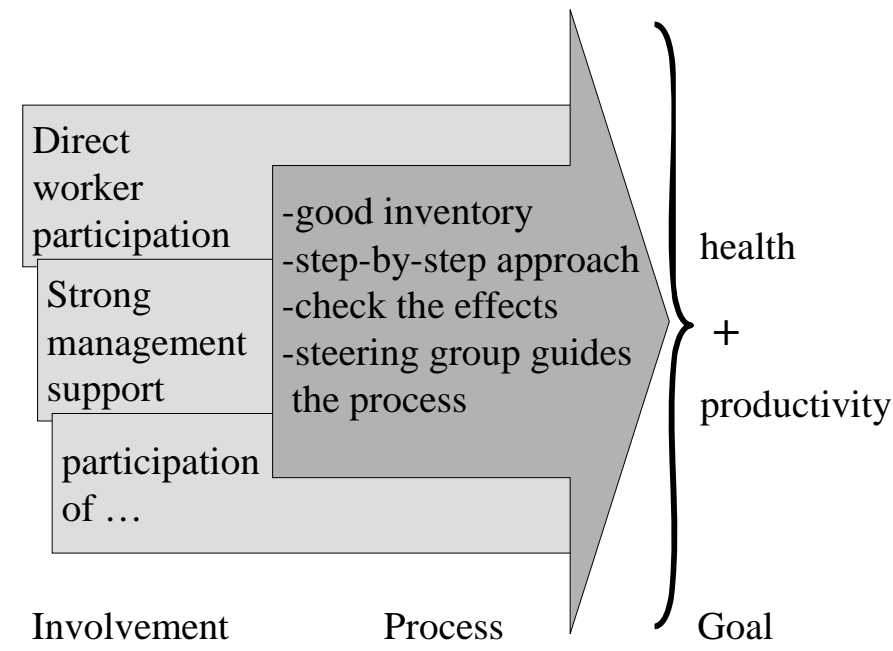

Fig. 1. Model to summarize the success factors described in the literature.

In figure 1 a summary of the success factors is shown. The first two factors concern the involvement of the groups, the next four concern the approach or process and the last two focus on the content or goal. The last two ('not only health issues' and 'include cost-benefit ratios') are connected to the topic of this paper: comfort and productivity. Regarding the first two a comment has to be made. In several studies (e.g. Haines et al., 2002; Jong and Vink, 2000; Vink and Kompier, 1997; Vink et al., 2005) it is mentioned that for a successful project also attention has to be paid to the participation of other stake holders, like ergonomists, facility management, occupational health representatives, suppliers, designers, engineer. Therefore, in the model shown in figure 1 a box is added 'participation of ...' indicating that it depends on the context and goal, which additional participant should be involved.

Regarding the process four success factors are mentioned. The inventory at the beginning is important to take the needs of the target groups into account and to find out whether improvements are possible. The step-by-step approach gives a lucid holdfast and structure to all participants. The structure also makes it possible to monitor the process towards the end result (a more productive and comfortable working environment). The steering group is needed to have a formal group responsible for the progress, which is known by all participants and capable to decide on how to proceed. Checking the effects in an early stage is useful to test feasibility of the innovations, keep the motivation for the project and if needed to adjust the process or goal in an early phase. 
Having said that involvement is important, it is interesting to know what kind of experiences end-users have that make them positive about the process and the chance of gaining the increase in productivity and comfort.

\subsection{A hypothesis on the process towards better comfort and productivity}

As is stated above, productivity and comfort are end-results of a process. So, a part of its success is determined by the way the process is organized. However, another part is determined by the artifact that is designed and by the experiences of the involved parties. Uotilla et al. (2005) made a schema on how positive emotions could be connected to the physical environment and activities (see fig.2). Based on an analysis of semistructured focus group interviews, they made a model for interpreting the relationship between wow and flow and interaction. They distinguish between active participation in an activity and passive experiences with a product. The wow-experience is more related to a passive product perception and a flow experience is more related to active participation. Wow could be described as a positive experience related to desire, surprise and fascination (Desmet et al., 2005). Some studies even mention that this positive experience increases sales (Gutman, 1982). Flow is an optimal experience or a positive arousal level reached by being occupied by achieving your goal (Csikszentmihalyi, 1997).

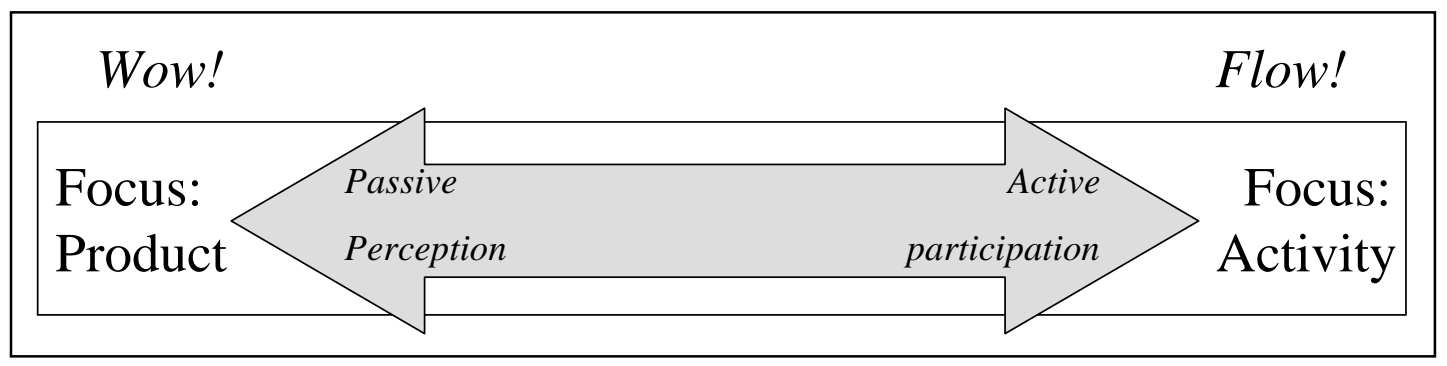

Fig. 2. The model of Uotila et al. (2005). The wow-experience is more related to a passive product perception and a flow experience is more related to active participation.

If it is agreed that positive experiences play a role in design, positive passive perceptions could be measured by making potential end-users looking at or using prototypes. Positive emotions (like saying 'wow') elicited by a prototype could increase the chance that the end-product is more appreciated. In designing working environments the process of design could be more of importance. Following the model of Uotila et al. (2005), this means that end-users that are more close to a flow during the process of design, would appreciate the final working environment more. According to Csikszentmihalyi (1997), a condition that increases the chance of flow is having the possibility to being in control. Based on this philosophy a hypothesis could be formulated: End-users are more enthusiastic about the new work environment if they are empowered and have a positive experience during the (thus increasing the chance of flow) in the process of design. 
The hypothesis formulated is based on the situation that there is a design process with participation of workers and management. The goal of the process is to arrive at a more comfortable and productive working environment.

In this case the chance of success increases by empowerment (making the end-user responsible for deciding on the next step in the process) and positive experiences with the potential improvement of end-users (end-users feel or see the benefits).

\section{Method}

To check whether this hypothesis is useful in evaluating cases, four welldescribed participatory ergonomics cases were evaluated with special attention for the empowerment and positive experiences with potential improvements. From approximately 100 participatory ergonomics cases available at TNO four were selected based on the following selection criteria:

-the project should be documented regarding the approach and the results in such a way that a distinction can be made in the role of the employees (empowerment or consultation) and the effects, -in all cases information should be available that the management supported the process, -in an early stage an inventory had to be made of bottle necks in production and health or comfort problems, -a stepwise approach should be used, -a steering group or other group leading the process should be defined, -the effects should be studied in more then in one stage of the project, -the project should concern a work environment improvement and an ergonomist should be involved, -data should be available on how end-users experienced ideas and prototypes of the product, -it should be focused on comfort and productivity, -it should be published in the international literature, and -two cases should be successful and two not.

The cases are described first, followed by a comparison and evaluation. It is expected that both cases with empowerment should increase the chance of 'flow' be the more successful cases and the cases with consultation the less successful ones. Another expectation is that the cases with more positive experiences with precursors of the new environment are also more successful.

\section{Results and discussion}

The selection of the cases appeared to be arbitrary, because for instance a distinction could be made in the role of employees and information was available regarding management support in many cases. Nevertheless, four cases were chosen that were most documented 'best' regarding the selection criteria, because illustration of the hypothesis is an essential part of this paper. The four cases chosen differed regarding the success rate, but also regarding the dependency of other employees in the group. In two cases individual employees could change their work station independent from other workers and in two cases it was a group decision. 


\subsection{Case 1. Success case with individual decision possibilities at the office}

In a study of Vink and Kompier (1997) a step-by-step approach to better work was applied, aimed at reducing mental and physical workload in office work. This approach was evaluated. The approach consisted of six steps including the definition of the problem, selection of solutions and testing the solutions. After every step the workers proposed how to continue and a steering group led by the management decided on this proposal. The workers identified the problems, developed ideas for improvement, tested improvements and chose them. Height-adjustable furniture was bought and organizational measures were taken to reduce the mental load. Examples of organizational measures were better appointments on earlier delivering information and divide between work that has to be done before a certain date and work that can be postponed (prioritizing). Finally, some workers were trained to encourage the continuation of adjustments and train new employees on the ergonomically ideal work station and work organization. As a result, most workplaces were adjusted and more than half of the subjects took organizational measures (see table 1). The approach was considered worthwhile, despite the fact that it is time consuming because it took about one year to arrive at better working conditions. The discomfort was reduced especially in the neck-shoulder region and the productivity was improved, especially by a more transparent and efficient process.

Table 1. Percentage of employees having adjusted the work $(n=29)$, and percentage of those employees with back or neck complaints $(n=18)$ that report a positive effect of these adjustments on back and neck complaints (Vink and Kompier, 1997).

\begin{tabular}{llc}
\hline \multicolumn{1}{c}{$\begin{array}{c}\text { Workers with } \\
\text { adjustments (\%) }\end{array}$} & $\begin{array}{c}\text { Workers reporting } \\
\text { positive effects on }\end{array}$ & \\
& & neck/back (\%) \\
\hline Chair height adjustment & 73 & 67 \\
Table height adjustment & 83 & 67 \\
VDU-screen position adjustment & 69 & 50 \\
Keyboard position adjustment & 34 & 11 \\
Addition of document holder & 14 & 17 \\
Addition of inclined desk & 31 & 11 \\
Agreements with other departments & 48 & 28 \\
Addition of telephone days & 24 & 11 \\
A new planning of activities & 59 & 28 \\
More varying work tasks & 48 & 28 \\
Setting priorities in work & 100 & 28 \\
\hline
\end{tabular}




\section{2 case 2. Failure case with individual decision possibilities in installation work}

In this case (Jong and Vink, 2000) an installation company aimed at reducing the musculoskeletal discomfort and improving the efficiency in work. Employees were stimulated to improve their work station. The design process consisted of six steps from analysis of the problems to evaluation of the improvements. Brainstorm sessions were organized with employees and experts. Employees, staff or external experts built the most promising ideas. These were tested and if successful, implemented. A group led by the communication department was responsible for the process. A book was made with examples of the developed solutions (see fig. 3) describing the effect on productivity and musculoskeletal loading. This book was made available on all sites of the company (app. 30) and employees were encouraged to develop new solutions. Employees received freedom to make their improvements and were encouraged to develop more. Prizes were given to the best innovations. After the project in total 198 devices were in use for 7,000 workers (3\%). All devices contributed to a reduction in discomfort and increase in productivity. The company considered the project successful, because the return of investment was seen within a year. According to Rogers (1995) $2.5 \%$ of a group are innovators and adopt an improvement anyway. Therefore, from a scientific point of view this case can be seen as a failure.

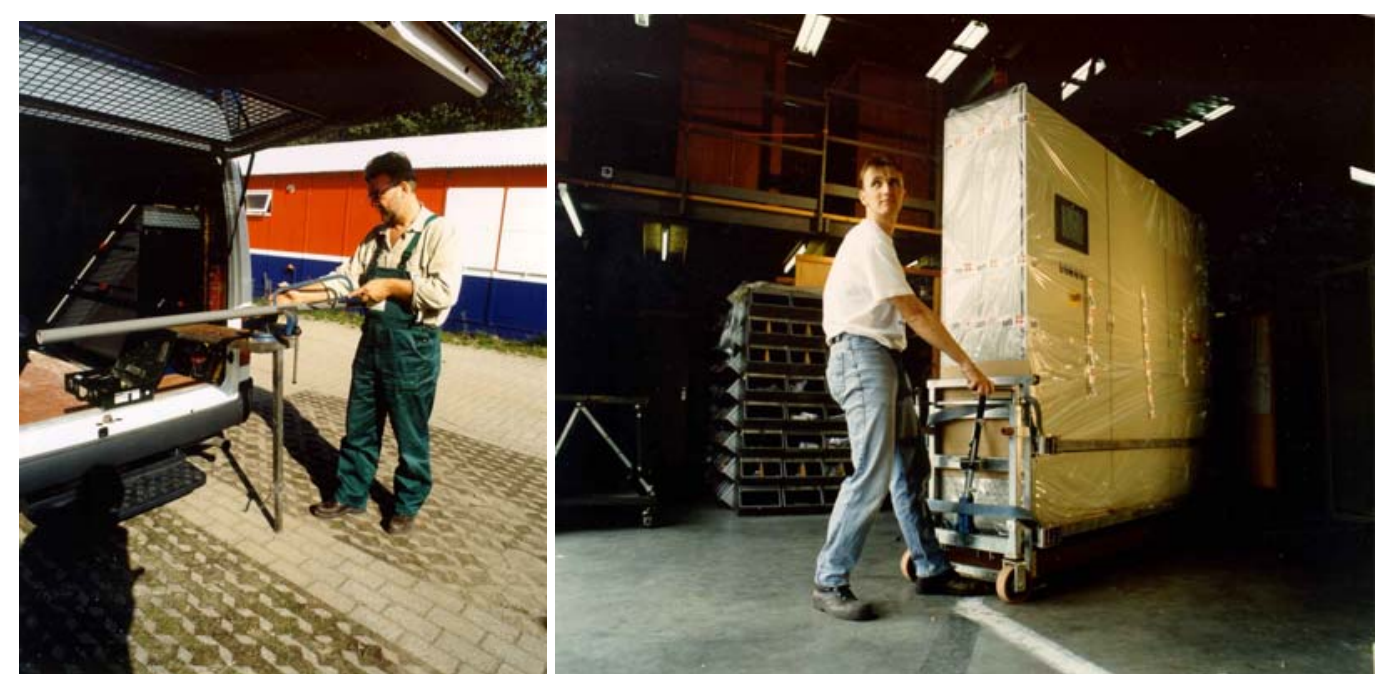

Fig. 3. Examples of improvements published in a book developed by end-users. Left: a height adjustable mobile workbench reducing bending and giving a better view on the work. Right: a transport system for cupboards with electronics preventing lifting and carrying and making work possible with fewer workers.

In a company that produces electric razors in very large volumes (see fig. 4); an experiment was performed to study the effect of workplace adjustment on the productivity and the discomfort of the workers (Rhijn et al., 2005). In many work stations in this company, just as in many other companies, the location of supply containers, from which components have to be picked, was designed by software. However, experts agreed that there is room for further improvement. A problem was that large numbers of 
different components needed to be at hand simultaneously. This leads to frequent, extended reaching and much arm elevation. Consequently, risks for shoulder discomfort and pain could increase. It was decided to do an experiment, to see if it is possible to lower the picking heights to comfortable levels. The approach was participatory as experts together with management and employees defined the problem and the improvement. The effects were measured and based on the results a decision was made whether or not to change the work stations in what way. The management decided to improve, to do the test and on the implementation.

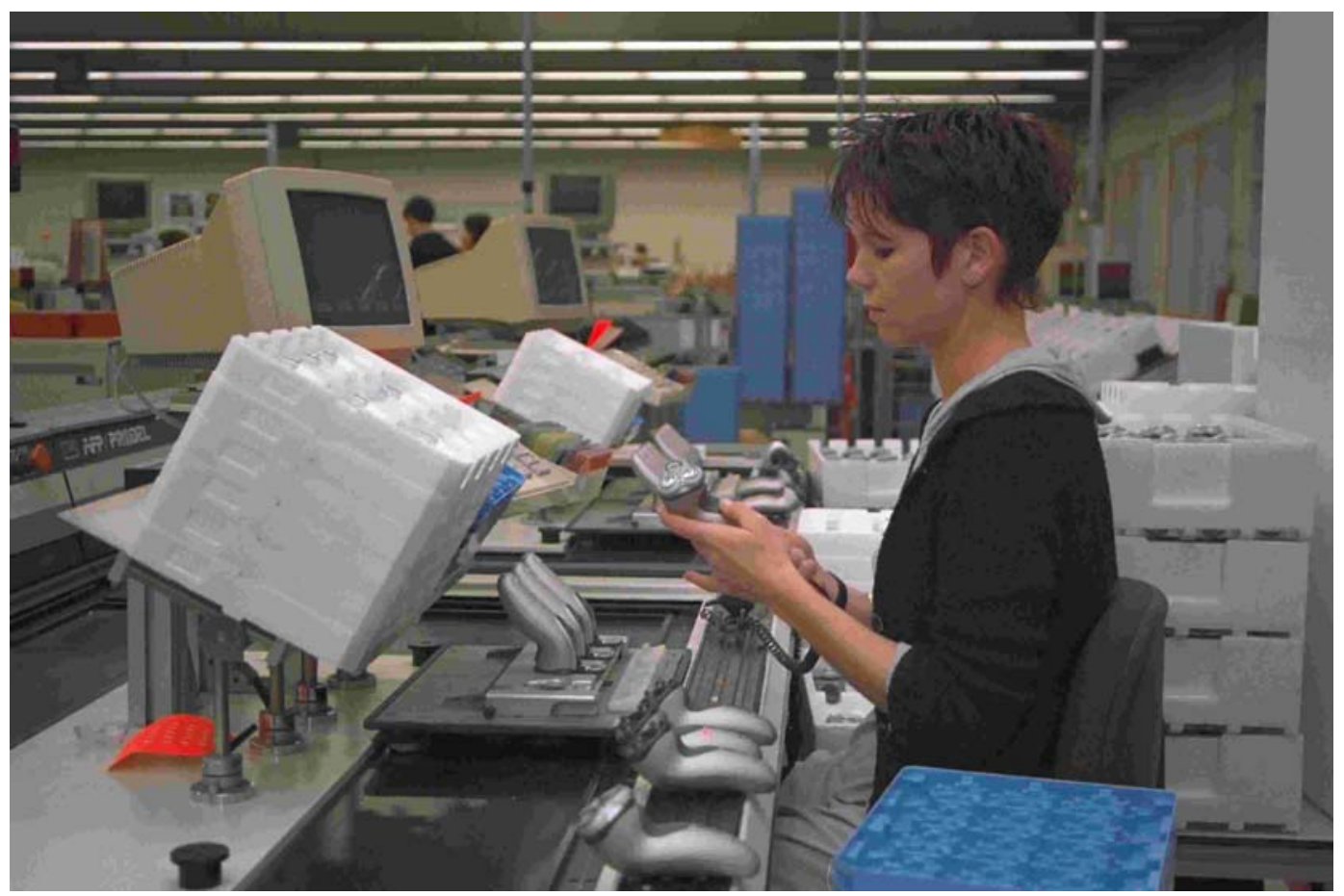

Fig. 4. A workstation that is improved of case 3: assembly work

\subsection{Case 3. Success case with group decision in assembly work}

In a company that produces electric razors in very large volumes (see fig. 4); an experiment was performed to study the effect of workplace adjustment on the productivity and the discomfort of the workers (Rhijn et al., 2005). In many work stations in this company, just as in many other companies, the location of supply containers, from which components have to be picked, was designed by software. However, experts agreed that there is room for further improvement. A problem was that large numbers of different components needed to be at hand simultaneously. This leads to frequent, extended reaching and much arm elevation. Consequently, risks for shoulder discomfort and pain could increase. It was decided to do an experiment, to see if it is possible to lower the picking heights to comfortable levels. The approach was participatory as experts together with management and employees defined the problem and the improvement. The effects were measured and based on the results a decision was made 
whether or not to change the work stations in what way. The management decided to improve, to do the test and on the implementation.

Table 2 shows a significant effect of workplace condition. In the low workplace condition, the maximum acceptable work pace was significantly higher than in the high workplace condition. The difference between the high and the low condition was 1.0 product per minute. This implies a difference in work pace of $10.6 \%$. This was accompanied by a reduction in discomfort. The project is defined as a success as the management, engineers and employees decided to change the work stations.

Table 2 Maximum Acceptable Work Pace (MAWP) Expressed in Number of Products per Minute and as the Average across Subjects Localized Musculoskeletal Discomfort (LMD) in the Neck and Shoulders as Measured at the End of the Test (after 50 Minutes)

\begin{tabular}{lll}
\hline Condition & Average MAWP (range) & Average discomfort (sd) \\
\hline & & \\
Workplace high & $9.4(6.7-13.0)$ & $1.1(1.0)$ \\
Workplace low & $10.4(7.2-14.6)$ & $0.4(0.6)$ \\
\hline
\end{tabular}

\subsection{Case 4. Failure case with group decision possibilities in construction work}

Molen et al. (2005) studied in a randomized control trial the effect of a participatory approach where bricklayers and assistant bricklayers are involved in changing their work station. Ten bricklaying companies were randomly assigned either to an intervention group which was subjected to the participatory approach $(n=5)$ or to a control group $(n=5)$. The approach consisted of a consultant-supported six-step approach in which different stakeholders from the company participated. In the steps, which consumed six months, the bricklayers and assistants were informed about the risks of the old way of working and on possibilities of improving the work and where to buy products. The end-users were encouraged to test the products. Bricklayers and bricklayers' assistants in the intervention group $(n=65)$ and the control group $(n=53)$ were followed for six months and their use of four ergonomic measures was compared. These measures consisted of adjusting working height when picking up bricks (see fig. 5) and mortar, adjusting working height for bricklaying at the wall side, mechanizing the transport of bricks (see fig. 6) and mechanizing the transport of mortar. The use of ergonomic measures was assessed by means of worksite observations and questionnaires at baseline and after six months. A work group in the company was responsible for the process and management decided.

The participatory ergonomics approach had no statistically significant effect on the use of any of the four ergonomic measures either at group or at individual level. No companies in the intervention group passed through all six steps. 


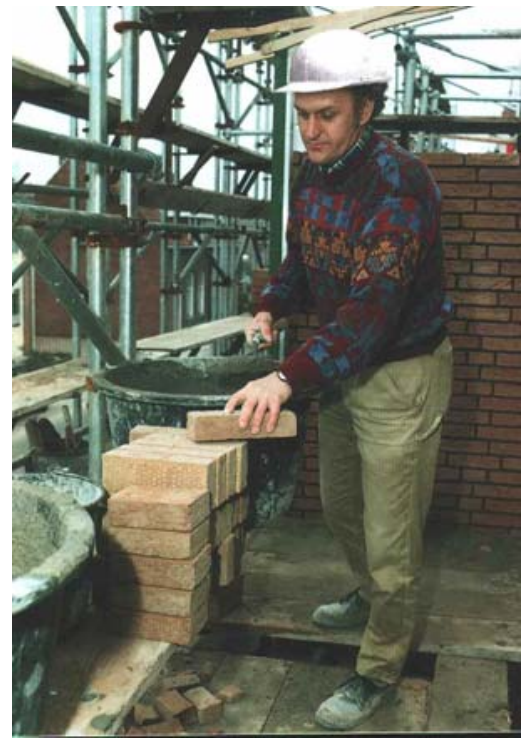

Fig. 5. Working with the bricks on a shore reduces bending.

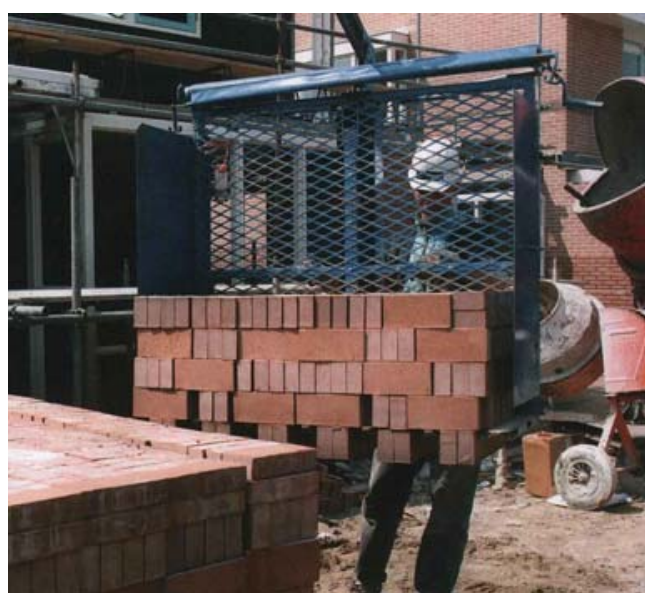

Fig. 6. A system developed to mechanize the manual transport of bricks.

\subsection{Comparison of the four cases}

In table 3 a summary of some characteristics of the cases is shown. In all situations a stepwise approach was chosen and management and ergonomists supported the projects. In case 1 and 2 the employee participation could be typified as close to empowered and in case 3 and 4 it was closer to consultation.

The main difference between the cases is the way employees are involved: empowerment or consultation and the way employees experience the potential new work environment. It was expected that both cases with empowerment and positive experience with the end product would give the best results. The employees could become enthusiastic about the improvement, because they are in control and experience the positive effects before the end-result is implemented.

For the first case this positive effect is shown. In this case employees were allowed to choose their own work station layout and influence the organization of work (empowerment). Employees have learned to evaluate the improvements and are able to choose and evaluate the consequence of changes in the workstation and organization. The work and environment limit some possibilities, but the employees have enough control to change the work. They tested various new ways of working and work stations and could experience how it works. This positive experience could have played a role in the success.

In the second case the effect of empowerment is less obvious. The employees were empowered to change their work. They could buy or make new equipment, but they had to be very creative to think of new solutions applicable for their specific tasks. Of course they have examples of others, who developed improvements in other situations, but transferring this to their own work environment is not easy. Probably because the lack of support from ergonomists or designers, ideas seen in one work area (e.g. transporting cupboards, see fig. 3) could not be transferred to another work area (e.g. transporting 
central heating elements). Only 3\% did really implement the improvements. As a result the end-users didn't experience positive effects of prototypes.

Table 3. Some characteristics of the four cases. + means that the factor could be distinguished. ++ means that there was much explicit attention for this factor. Light grey is involvement of stakeholders, dark grey concerns the process characteristics (see fig. 1)

\begin{tabular}{|c|c|c|c|c|}
\hline Case & 1 office & 2 Installation & 3 assembly & 4 bricklaying \\
\hline Project focus & \begin{tabular}{|l|} 
Discomfort and \\
work organization
\end{tabular} & $\begin{array}{l}\text { Productivity and } \\
\text { physical workload }\end{array}$ & $\begin{array}{l}\text { Productivity and } \\
\text { discomfort }\end{array}$ & Physical workload \\
\hline $\begin{array}{l}\text { Empowerment of } \\
\text { employees }\end{array}$ & ++ & ++ & & \\
\hline \begin{tabular}{|l} 
Consultation of \\
employees
\end{tabular} & & & ++ & ++ \\
\hline $\begin{array}{l}\text { Management } \\
\text { support }\end{array}$ & + & + & + & + \\
\hline Ergonomists support & + & + & ++ & + \\
\hline Inventory & ++ & + & + & + \\
\hline Stepwise approach & + & + & + & + \\
\hline $\begin{array}{l}\text { Steering group or } \\
\text { likewise group }\end{array}$ & ++ & ++ & + & ++ \\
\hline \begin{tabular}{|l|} 
Effects studied \\
during the process
\end{tabular} & ++ & + & ++ & + \\
\hline $\begin{array}{l}\text { Positive experience } \\
\text { with precursors of } \\
\text { the end-product }\end{array}$ & ++ & & ++ & \\
\hline Success & Yes & No & Yes & no \\
\hline
\end{tabular}

-table 3 around here-

In the third case the workers were not empowered, but are asked to test various improvements in the assembly line. In this case employees are interdependent, because a groups works in one assembly line. Some employees were involved in the process of gathering the first ideas and they experienced effects in an early phase of the process. They experienced the effects of reducing reaching distances in mixed reality environments. All employees were involved in comparing the new design of the line compared with the old situation. They were asked to complete a questionnaire on local 
postural discomfort. In this way they were made aware of the differences between the old and the possible new situation. They experienced the difference. The case is successful too. So, probably some forms of consulting employees in combination with positive experience also have there positive effects.

In the fourth case, which has been described recently (Molen et al., 2005), employees are not empowered. The management of the company had to find possibilities to test improvements. Even the management was partly empowered. The management was dependent of the contractors whether or not to use mechanical transport systems or scaffoldings that reduce the bending of the back. Only in a very few situations improvements could be tested partly and employees could hardly experience differences between old and new. For instance, sometimes the crane could not be used, because the main contractor had no crane or needed the crane himself. The project was not successful in terms of productivity and comfort increase.

These four examples show that the theory has opportunities to typify differences between projects and explain differences in success. The four cases also show that empowerment is not the key to success in all situations. Sometimes employees do not have enough knowledge (case 2) and sometimes employees do not have enough influence to change their work situation (case 3 and 4).

The consequence of experiencing the effects is that employees feel that they are in control. This fact that success is easier achieved if employees experience control and are actively involved has been described before. Norberg (2005) states that 'It's not just the money that makes high-earners happier than low-earners - more important is their way of life-being active, being creative, and experiencing control of your life. Other research also tells us that optimism works: 'People who think that they are in control of their lives go on to be more successful than others' (Fredrickson, 1998). So, if employees experience control and are optimistic about the feasibility, this could be an important factor in why a participatory ergonomics project is successful.

Another explanation could be that experiencing differences between alternatives is important. In this way participants understand why the improvement is better and convincing is not needed. It's not only that employees experience the difference and learn why one situation is better than the other. In many ergonomic design projects, an optimum has to be found. In designing a work station along an assembly line under load and overload could be hazardous. Under load is not beneficial for the company (unproductive) and the worker (no challenge). Overload could have the consequence of stress and musculoskeletal injuries (worker), which leads to mistakes in the production work and drop out of workers (see fig. 7). The challenge for the future is to get the 'situation in production lines' in the lowest part of the curve (Vink and Stahre, 2005).

This can be applied to working height as well. There is an optimum working height where the work can be performed best regarding comfort and productivity. In fact in most ergonomic situations an optimum has to be found and in most situations the theory is not developed well enough to predict the ideal working height and experiments are needed to find the optimum. Ideally, these experiments are performed at the work place with the employees. Thereby, the employees will experience control, perceive/experience the differences and understand the reason for change. 


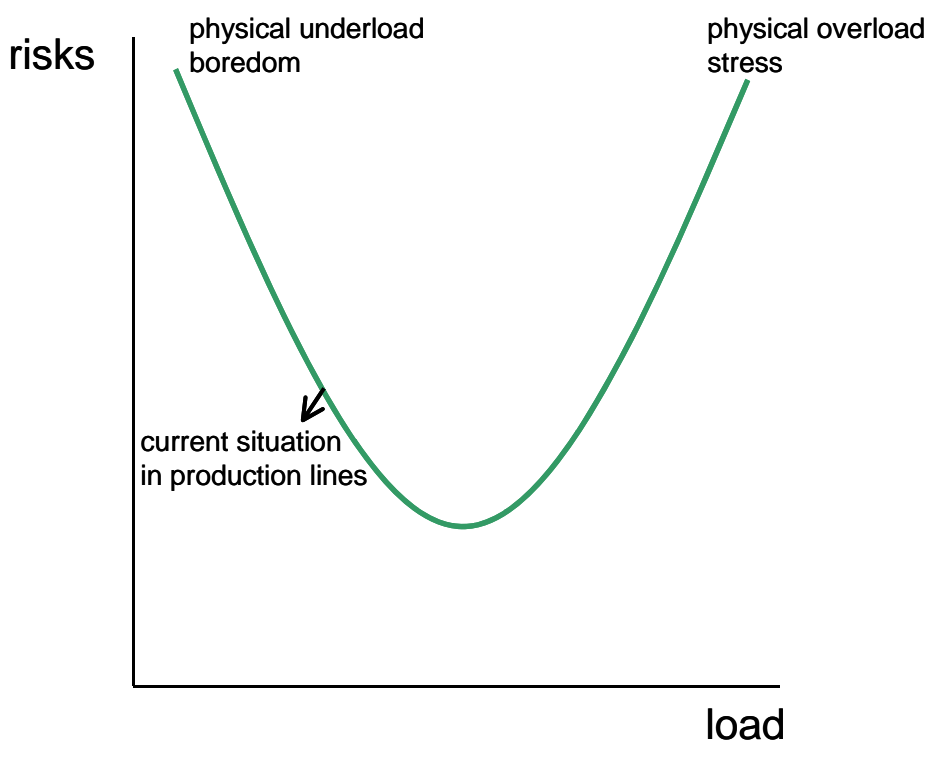

Fig. 7. To increase performance of the company employees should work at the optimum between overload and under load (Vink and Stahre, 2005)

\subsection{Reflection}

There is no doubt that a selection of four cases is too small to draw conclusions. However, the factors 'strong management support', 'making a good inventory', 'using a stepwise approach', 'having group steering the process', 'study the effects' and ergonomists support' are also described in various other studies (e.g. Haines et al, 2002; Looze et al., 2001; Koningsveld et al., 2005). The conclusion could be drawn that 'experiencing the effects of the improvement' and 'empowerment of employees' are two important additional factors. However, the importance is still unknown. Furthermore, the factors do not exclude themselves. It could be that in a project where employees are empowered employees have more possibilities to experience the effects and experience control as well.

\section{Conclusion}

It was the aim of this paper to convince ergonomists to focus more on the positive side of ergonomics. In this paper the positive aspects increasing comfort and productivity 
are highlighted. Many success factors are described in the literature leading to better comfort and higher productivity, but there is no universally agreed list of factors. A model is made (see fig. 1) which classifies the success factors in 'involvement', 'process' and 'goal' of the ergonomics project. Regarding involvement many studies agree that active participation of end-users and management contributes to success. Regarding 'process' a good inventory of the problems, a structured step-by-step approach, a steering group and good check of the effects are success factors.

Based on the above mentioned findings and theories of Uotila et al. (2005) and (Csikszentmihalyi, 1997) it is hypothesized that the chance of success increases by empowerment (making the end-user responsible for deciding on the next step in the process) and if end-users have positive experiences with the potential improvement (endusers feel or see the benefits). Especially, the last part of the hypotheses is supported by a selection of four cases.

Based on the evaluation of four cases and some theory it can be concluded that the hypothesis is useful for evaluating cases. The hypothesis stimulates awareness regarding end-users experiencing control, optimism about the feasibility and feeling differences between alternatives. Studying the optimum between alternatives is also needed because ergonomics often strives for the optimum situation. If these alternatives are studied in an experiment where end-users or employees experience the differences this could be favorable and the chance of higher comfort and better productivity increases. This is also closely related to the feeling of having control. "People who think that they are in control go on to be more successful than others"

Another advantage of studying the optimum before introducing the improvement is that knowledge is increased. If ergonomists share the findings of these projects regarding optimal work environments it would also contribute to the knowledge increase in the field of ergonomics.

\section{References}

Beevis, D., Slade, I.M., 2003. Ergonomics_costs and benefits. Appl. Erg. 34(5), 413-418.

Brauer, W., Lozano-Ehlers, I., Greisle, A., Hube, G., Keiter J., Rieck, A., 2003. Office 21 - Push for the fututre better performance in innovative working environments, Fraunhofer, Cologne/Stuttgart:

Bronkhorst, R.E., Krause, F., 2005, Designing comfortable passengers seats, in: Vink, P. (Ed.) Comfort and Design: Principles and Good Practice. CRC Press, Boca Raton, pp. 155-168.

Csikszentmihalyi, M., 1997. Finding flow. The psychology of engagement of everyday life, HarperCollins Publishers, London.

Desmet, P.M.A., Porcelijn, R., Dijk, M.B. van, 2005. How to design wow. Introducing a layered-emotional approach, in: Wensveen, S. (Ed), Proceedings of the conference Designing Pleasurable Products and Interfaces, TU Eindhoven, Eindhoven, pp. 71-89.

Eikhout, S.M., Vink, P., Grinten, M.P. van der, 2005. Comfort Effects of Participatory Design of Screwdrivers, in: Vink, P. (Ed.) Comfort and Design: Principles and Good Practice. CRC Press, Boca Raton, pp. 207-217 
Eklöf, M., Ingelgård, A., Hagberg, M., 2004. Is participative ergonomics associated with better working environment and health? A study among Swedish white-collar VDU users. Int. J. of Ind. Erg. 34(5), 355366

European Foundation for the Improvement of Living and Working Conditions, 1999

Communique July/August, 1999, EFILWC 2, Dublin

Fredrickson, B.L., 1998. What good are positive emotions? Review of General Psychology 2, 300-319.

Gutman, J., 1982. A means-end chain model based on consumer categorization process. J of Marketing 46, 60-72

Haines, H., Wilson, J.R., Vink, P., 2002. Koningsveld, E.A.P., Validating a Framework for Participatory Ergonomics. Ergonomics 45(4), 309-327.

Hedge, A., Sakr, W., 2005. Workplace effects on office productivity: A macroergonomic framework, in: Carayon, P., Robertson, M., Kleiner, B., Hoonakker, P.L.T., Human factors in Organizational Design and Management - VIII, IEA Press, Santa Monica, pp. 75-80

Hendrick, H., 2001. Good ergonomics is good economics, HFES press, Santa Monica

ISO 9241-5:1998 Ergonomic requirements for office work with visual display terminals (VDTs) Part 5: Workstation layout and postural requirements)

Jong, A.M. de, Vink, P., 2000. The adoption of technological innovations for glaziers; evaluation of a participatory ergonomics approach. Int. J. Ind. Erg 26, 939-46.

Koningsveld, E.A.P., Dul, J., Rhijn, G.W. van, Vink, P. 2005. Enhancing the impact of ergonomics interventions. Ergonomics 48(5), 559-580.

Kuorinka, I., 1997. Tools and means of implementing participatory ergonomics. Int. J. of Ind. Erg. 15, 365-370.

Looze, M.P. de, Rhijn J.W. van, Schoenmaker, N., Grinten, M.P. van der, Deursen J. van, 2005. Productivity and Discomfort in Assembly Work: The Effects of an Ergonomic Workplace Adjustment at Philips DAP. In: Vink, P. (Ed.) Comfort and Design: Principles and Good Practice. CRC Press, Boca Raton, pp.129-136.

Looze, M.P. de, Urlings I.J.M., Vink, P., Rhijn, J.W. van, Miedema, M.C., Bronkhorst, R.E. and Grinten, M.P. van der, 2001. Towards successful physical stress reducing products: an evaluation of seven cases. Appl. Erg. 32, 525-534.

Molen, H.F. van der, Sluiter, J.K., Hulshof, C.T.J., Vink, P., Duivenbooden, C. van, Holman, R., FringsDresen, M.H.W. 2005. Implementation of participatory ergonomics intervention in construction companies. Scand J Work Environ Health 31(3):191-203.

Norberg, J., 2005. In Defense of Global Capitalism, Cato Institute, Washington

Pfeffer, J., Veiga. J.F., 1999. Putting people first for organizational success. Academy of Management Executive 13(2), 37-48.

Rhijn, J.W. van, Looze, M.P. de, Groenesteijn, L., Hagedoorn-de Groot, M.D., Vink, P., Tuinzaad, G.H., 2005. Productivity and Discomfort in Manual Assembly Operations. In: Vink, P., (Ed.) Comfort and Design: Principles and Good Practice. CRC Press, Boca Raton pp.111-128. 
Rhijn, J.W. van, Looze, M.P. de, Tuinzaad, G., Groenesteijn, L., Groot, M.D. de, Vink. P.. 2005. Changing from batch to flow assembly in the production of emergency lighting devices. Int. Journal of Production Research 43(17), 3687-3701

Rogers, E.M., 1995. Diffusion of innovation, free press, New York.

Rosecrance, J., Dpuphrate, D., Cross, S.. 2005. Integration of participatory ergonomics and lean manufacturing: a model and case study. in: Carayon, P., Robertson, M., Kleiner, B., Hoonakker, P.L.T. (Eds.) Human factors in Organizational Design and Management - VIII, IEA Press, Santa Monica, pp. $437-$ 442

Uotilla, M., Falin, P., Aula, P., 2005. Experience of luxury and pelasure with products. in: Wensveen, S. (Ed.) Proceedings of the conference Designing Pleasurable Products and Interfaces, TU Eindhoven, Eindhoven pp 91-103.

Vink, P., 2005. (Ed.) Comfort and Design: Principles and Good Practice. CRC Press, Boca Raton

Vink, P., Jong, A. de, Koningsveld, E.. 2005. Making Money with Participatory Ergonomics. in: Carayon, P., Robertson, M., Kleiner, B., Hoonakker, P.L.T. (Eds.) Human factors in Organizational Design and Management - VIII, IEA Press, Santa Monica, pp. 443-448, 2005

Vink, P., Kompier, M.A.J., 1997. Improving office work: a participatory ergonomic experiment in a naturalistic setting. Ergonomics 40(4), 435-49.

Vink, P., Stahre, J., 2005. The future of human factors in manufacturing. in: Carayon, P., Robertson, M., Kleiner, B., Hoonakker, P.L.T. (Eds.) Human factors in Organizational Design and Management - VIII, IEA Press, Santa Monica, pp. 211-216.

Wilson, J.R., 1995. Solution ownership in participative work redesign: The case of a crane control room. Int. J. of Ind. Erg. 15: 329-344.

Wilson, J.R. , Haines, H.M., 1997. Participatory ergonomics, in: Salvendy, G., (Ed.) Handbook of Human Factors and Ergonomics (2nd edition) J. Wiley \& Sons, Chichester pp 490-513. 